D) Check for updates

Cite this: Food Funct., 2019, 10, 2528

\section{(+)-Catechin inhibits heart mitochondrial complex I and nitric oxide synthase: functional consequences on membrane potential and hydrogen peroxide production}

\author{
Darío E. Iglesias, (D) a,b Silvina S. Bombicino, ${ }^{a}$ Alberto Boveris ${ }^{a, b}$ and \\ Laura B. Valdez (iD *a,b
}

\begin{abstract}
In order to study the in vitro effect of flavan-3-ol (+)-catechin on the enzymatic activities of mitochondrial complex I and nitric oxide synthase (mtNOS), as well as the consequences on the membrane potential and $\mathrm{H}_{2} \mathrm{O}_{2}$ production rate, isolated mitochondria from rat heart were exposed to $3 \mathrm{nM}$ to $100 \mu \mathrm{M}$ (+)-catechin. $\mathrm{NADH}-\mathrm{Q}_{1}$ reductase (complex I) and $\mathrm{mtNOS}$ activities were inhibited $25 \%$ and $50 \%$, respectively, by the addition of $10 \mathrm{nM}(+)$-catechin to the reaction medium. Moreover, in the $\mathrm{nM}$ range, (+)-catechin decreased state 4 mitochondrial membrane potential by about $10 \mathrm{mV}$, but failed to change the membrane potential measured in the presence of ADP. (+)-Catechin (10 nM) inhibited not only complex I activity, but also the $\mathrm{H}_{2} \mathrm{O}_{2}$ production rate (35\%) sustained by malate-glutamate, in accordance with the decrease observed in mitochondrial membrane potential. Considering (+)-catechin concentrations lower than $10 \mathrm{nM}$, linear and positive correlations were obtained between mitochondrial complex I activity and either $\mathrm{NO}\left(r^{2}=0.973\right)$ or $\mathrm{H}_{2} \mathrm{O}_{2}$ production rates $\left(r^{2}=0.958\right)$, suggesting a functional association among these parameters. Altogether, the results indicate that $(+)$-catechin, at nM concentrations, inhibits mitochondrial complex I activity, leading to membrane potential decline and consequently to reduction in $\mathrm{H}_{2} \mathrm{O}_{2}$ and $\mathrm{NO}$ production rates. The decrease in mtNOS activity could also be a consequence of the direct action of $(+)$-catechin on the NOS structure, this effect being in accordance with the functional interaction between complex I and mtNOS, as previously reported.
\end{abstract}

Received 20th September 2018 Accepted 29th March 2019

DOI: $10.1039 / c 8 f \circ 01843 j$

rsc.li/food-function semiquinone. ${ }^{7}$ In the mitochondrial matrix, Mn-superoxide dismutase (Mn-SOD) dismutates $\mathrm{O}_{2}{ }^{-}$to produce hydrogen peroxide $\left(\mathrm{H}_{2} \mathrm{O}_{2}\right) \cdot{ }^{8-11}$ In addition, $\mathrm{O}_{2}{ }^{-}$reacts with nitric oxide (NO), the latter species is produced by mitochondrial nitric oxide synthase (mtNOS), an isoenzyme of the NOS family located in the mitochondrial inner membrane..$^{12-14}$ The reaction between $\mathrm{O}_{2}{ }^{-}$and NO yields the strong oxidant and nitrating compound, peroxynitrite $\left(\mathrm{ONOO}^{-}\right)$. When the steady-state concentration of $\mathrm{ONOO}^{-}$is increased, tyrosine nitration, protein oxidation and damage to Fe-S centers might take place, ${ }^{15-17}$ leading to complex I inhibition. Dysfunction of complex $\mathrm{I}$ is found in clinical conditions such as Parkinson's disease ${ }^{18-21}$ ischemiareperfusion, ${ }^{22,23}$ endotoxic shock ${ }^{24}$ and aging; ${ }^{25-27}$ and it is usually accompanied by changes in mtNOS activity, ${ }^{20,22-25}$ increases in $\mathrm{H}_{2} \mathrm{O}_{2}$ and $\mathrm{ONOO}^{-}$production rates and oxidative and/or nitrosative damage. This finding agrees with the reported functional interaction between complex $\mathrm{I}$ and mtNOS ${ }^{28-31}$ and with the dependence of mitochondrial NO production on membrane potential. ${ }^{30,32,33}$

Many studies have shown that polyphenols attenuate the progression of diseases associated with oxidative stress and 
mitochondrial dysfunction. ${ }^{34,35}$ It has been described that, within the cells, mitochondria can accumulate flavonoids. ${ }^{36,37}$ Plant polyphenols - flavonoids and non-flavonoids - are reducing agents that function as antioxidants by virtue of the hydrogen-donating properties of their phenolic hydroxyl groups as well as by their transition metal-chelating abilities. The aromatic hydroxyl groups of flavonoids produce an antioxidant pharmacophore comparable to the chroman moiety of tocopherols. Indeed, a high reactivity of flavonoids with radicals such as $\mathrm{O}_{2}{ }^{-}$, hydroxyl radical ( $\left.\mathrm{HO}^{\circ}\right)$ and $\mathrm{NO}$ has been reported. ${ }^{38-40}$ However, the effectiveness of flavonoids as cellular antioxidants cannot be accounted for solely in terms of their chemical antioxidant capacity because of the lack of correlation between the reduction potential of flavonoids and their ability to afford protection against oxidative stress. ${ }^{41}$ Furthermore, the data from dietary bioavailability of flavonoids point out that the physiologic plasma concentration of total metabolites does not exceed $10 \mu \mathrm{M}^{42}$ The bioavailability of flavonoids also depends on the dietary sources, and it has been shown that total flavonoid metabolites can reach plasma concentrations of up to $4.0 \mu \mathrm{M}$ with an intake of $50 \mathrm{mg}$ aglycone equivalents, except for isoflavones that can reach higher concentrations. ${ }^{43}$ Thus, although many studies support the hypothesis that the protective effects of flavonoids are related to their intrinsic antioxidant properties, many other modes of action for catechins have been suggested. ${ }^{4-46}$ Indeed, it has been previously reported that flavonoids can cause high inhibition of cellular reactive oxygen species production through inhibition of redox enzymes like $\mathrm{NAD}(\mathrm{P}) \mathrm{H}$ oxidases, ${ }^{47,48}$ xanthine oxidase, ${ }^{49}$ monooxygenases, cyclooxygenases and lipooxygenases, ${ }^{50}$ as reviewed by Gutierrez-Merino et al. ${ }^{51}$

Considering that (+)-catechin, a flavan-3-ol present in green and black teas and many other plant foods, has shown beneficial effects on cardiovascular pathological processes, such as ischemia/reperfusion-induced tissue injury ${ }^{52}$ and hypertension, ${ }^{53}$ and that flavonoids can accumulate in mitochondria, ${ }^{36,37}$ the aim of this work was to study the in vitro effect of $(+)$-catechin, in the $\mathrm{nM}$ to low $\mu \mathrm{M}$ concentration range, on heart mitochondrial complex I and mtNOS activities, as well as the consequences on the membrane potential and $\mathrm{H}_{2} \mathrm{O}_{2}$ production rate.

\section{Materials and methods}

\section{Drugs and chemicals}

The flavonoid (+)-catechin, recombinant nNOS (N3033, from rat brain) and other chemicals were purchased from Sigma Chemical Co. (St Louis, MO, USA). Other reagents were of analytical grade.

\section{Heart mitochondria isolation and mitochondrial membrane preparation}

Sprague-Dawley female rats of 6-7 weeks of age (200-220 g) were housed in cages in an environmentally controlled facility at $25{ }^{\circ} \mathrm{C}$. The animals were subjected to circadian light-dark cycles, fed standard rat chow, and provided water ad libitum. Animals were sacrificed under a $\mathrm{CO}_{2}$ atmosphere; hearts were removed, washed and weighed. The procedures used in this study were approved by the Animal Care and Research Committee of the School of Pharmacy and Biochemistry, University of Buenos Aires (CICUAL; 0027118/2017), and this investigation was in accordance with the International Guiding Principles for Biomedical Involving Animals (ICLAS).

The heart mitochondrial fraction was obtained from whole heart homogenates through differential centrifugation, using a Sorvall RC5C centrifuge (Sorvall-Instruments-Du Pont, Model RC5S). Hearts were homogenized in a glass-Teflon homogenizer in a medium consisting of $230 \mathrm{mM}$ mannitol, $70 \mathrm{mM}$ sucrose, $10 \mathrm{mM}$ Tris-HCl, and $1 \mathrm{mM}$ EDTA, pH 7.40 (MSTE) at a ratio of $1 \mathrm{~g}$ tissue per $9 \mathrm{ml}$ of medium. The homogenate was centrifuged at $700 \mathrm{~g}$ for $10 \mathrm{~min}$ to remove nuclei and cell debris, the sediment was discarded and the supernatant was centrifuged at $8000 \mathrm{~g}$ for $10 \mathrm{~min}$ to precipitate mitochondria. The pellet was washed twice and resuspended in the same buffer. ${ }^{54}$ This suspension consisted of mitochondria able to carry out oxidative phosphorylation. The whole procedure was carried out at $0-4{ }^{\circ} \mathrm{C}$.

Mitochondrial membranes were obtained by three cycles of freezing and thawing of mitochondrial preparations and homogenized by passage through a 25 -gauge hypodermic needle. ${ }^{55}$

\section{Mitochondrial complex I activity}

Complex I activity was studied following NADH-cytochrome c reductase (complex I-III) and NADH- $\mathrm{Q}_{1}$ reductase (complex I) activities. Absorbance changes were monitored using a Beckman DU 7400 diode array spectrophotometer, at $30^{\circ} \mathrm{C}$.

In order to measure $\mathrm{NADH}-$ cytochrome c reductase activity,

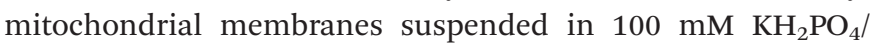
$\mathrm{K}_{2} \mathrm{HPO}_{4}, \mathrm{pH} 7.40$ (0.01-0.03 $\mathrm{mg}$ protein per $\left.\mathrm{ml}\right)$ were pre-incubated for $2 \mathrm{~min}$ in the absence or in the presence of 1.0 to 50 $\mathrm{nM}$ of (+)-catechin. Then, $0.2 \mathrm{mM} \mathrm{NADH}, 25 \mu \mathrm{M}$ cytochrome $\mathrm{c}^{3+}$, and $0.5 \mathrm{mM}$ KCN were added. Cytochrome $\mathrm{c}$ reduction was performed at $550-540 \mathrm{~nm}\left(\varepsilon=19 \mathrm{mM}^{-1} \mathrm{~cm}^{-1}\right)$ and the enzymatic activity was expressed as nmol cyt. $\mathrm{c}^{2+}$ per min per $\mathrm{mg}$ protein, taking into account the absorbance changes sensitive to rotenone $(1 \mu \mathrm{M})$ addition. ${ }^{56}$

$\mathrm{NADH}-\mathrm{Q}_{1}$ reductase activity was measured in a medium consisting of $10 \mathrm{mM}$ Tris-HCl, $1 \mathrm{mM}$ EDTA, and $50 \mathrm{mM} \mathrm{KCl}$, at pH 7.40. Mitochondrial membranes (0.01-0.03 $\mathrm{mg}$ protein per $\mathrm{ml}$ ) were pre-incubated for $2 \mathrm{~min}$ in the absence or in the presence of $10 \mathrm{nM}$ to $100 \mu \mathrm{M}(+)$-catechin. After that, $75 \mu \mathrm{M} \mathrm{NADH}$, $50 \quad \mu \mathrm{M} \quad$ 2,3-dimethoxy-5-methyl-6-(3-methyl-2-butenyl)-1,4benzoquinone (ubiquinone- 1 or $\mathrm{Q}_{1}$ ), $2 \mathrm{mM} \mathrm{KCN}$, and $1 \mu \mathrm{M}$ antimycin were added, and NADH consumption was carried out at $340-380 \mathrm{~nm}\left(\varepsilon=5.5 \mathrm{mM}^{-1} \mathrm{~cm}^{-1}\right)$. As the control, the effect of $1 \mu \mathrm{M}$ rotenone was tested. Complex I activity was expressed as nmol NADH per min per mg protein. ${ }^{57}$

\section{Nitric oxide synthase activity}

Nitric oxide synthase activity was determined performing the oxidation of oxyhemoglobin $\left(\mathrm{HbO}_{2}\right)$ to methemoglobin at 
577-591 nm $\left(\varepsilon=11.2 \mathrm{mM}^{-1} \mathrm{~cm}^{-1}\right)$ using a Beckman DU 7400 diode array spectrophotometer, at $37^{\circ} \mathrm{C} .{ }^{55,58}$

The NO production rate by heart mitochondrial membranes, i.e. mtNOS activity, was measured in a reaction medium consisting of $100 \mathrm{mM} \mathrm{KH}_{2} \mathrm{PO}_{4} / \mathrm{K}_{2} \mathrm{HPO}_{4}, \mathrm{pH}$ 7.40, $1 \mathrm{mM} \mathrm{CaCl} 2,100 \mu \mathrm{M} \mathrm{NADPH}, 10 \mu \mathrm{M}$ dithiothreitol (DTT), $4 \mu \mathrm{M} \mathrm{Cu}$, Zn-SOD, $0.1 \mu \mathrm{M}$ catalase, $1 \mathrm{mM}$ L-arginine, $20 \mu \mathrm{M}$ $\mathrm{HbO}_{2}$, and mitochondrial membranes (0.20-0.30 $\mathrm{mg}$ protein per $\mathrm{ml}$ ) pre-incubated for $2 \mathrm{~min}$ in the absence or in the presence of 1.0 to $25 \mathrm{nM}$ of (+)-catechin.

The NO production sustained by rat recombinant nNOS was measured in a reaction medium consisting of $50 \mathrm{mM}$ HEPES, pH 7.40, $1 \mathrm{mM} \mathrm{CaCl}_{2}, 100 \mu \mathrm{M} \mathrm{NADPH}$, $170 \mu \mathrm{M}$ DTT, $10 \mu \mathrm{M}$ tetrahydrobiopterin $\left(\mathrm{BH}_{4}\right), 1 \mu \mathrm{M}$ calmodulin, $50 \mu \mathrm{M}$ L-arginine, $5 \mu \mathrm{M} \mathrm{HbO}_{2}$ and $0.05-0.18$ units per $\mathrm{ml}$ nNOS. The effect of 3 and $10 \mathrm{nM}$ of (+)-catechin was tested. ${ }^{31}$

In order to consider the NOS inhibitor-sensitive $\mathrm{HbO}_{2}$ oxidation, control experiments adding $2 \mathrm{mM} \mathrm{N} \mathrm{N}^{\omega}$-monometil-Larginine (L-NMMA) were performed. The absorbance changes that were inhibited by L-NMMA were expressed as nmol NO per min per mg protein or nmol NO per min per U.

\section{Mitochondrial membrane potential}

Mitochondrial membrane potential $(\Delta \Psi)$ was determined by measuring rhodamine 123 (Rh-123) fluorescence at 503-527 nm ( $\left.\lambda_{\text {exc-em }}\right)$ with a Hitachi F-3010 spectrofluorometer, at $30{ }^{\circ} \mathrm{C} .^{32,59,60}$ Rhodamine- 123 was dissolved in ethanol and its concentration was assayed spectrophotometrically at $507 \mathrm{~nm}\left(\varepsilon=101 \mathrm{mM}^{-1} \mathrm{~cm}^{-1}\right)$. The ethanol concentration in the measuring medium was kept below $0.2 \%(\mathrm{v} / \mathrm{v})$.

The fluorescence of the media containing $150 \mathrm{mM}$ sucrose, $2 \mathrm{mM} \mathrm{MgCl}, 5 \mathrm{mM} \mathrm{KH} \mathrm{PO}_{4} / \mathrm{K}_{2} \mathrm{HPO}_{4}, 30 \mathrm{mM} \mathrm{KOH}$-HEPES, $\mathrm{pH} 7.40$, and $0.1 \mu \mathrm{M}$ Rh-123 was determined before addition of the mitochondrial suspension. This measurement was used as an indication of the total dye concentration ([Rh$123]_{\text {total }}$, in $\left.\mathrm{nmol} \mu \mathrm{l}^{-1}\right)$. The heart mitochondrial suspension (0.10-0.20 $\mathrm{mg}$ protein per $\mathrm{ml}$ ) was pre-incubated for $2 \mathrm{~min}$ in the absence or in the presence of $10 \mathrm{nM}, 100 \mathrm{nM}$ or $5.0 \mu \mathrm{M}$ $(+)$-catechin and added to the reaction media. In order to establish resting respiration (state 4), $6 \mathrm{mM}$ malate and $6 \mathrm{mM}$ glutamate were added. State 3 respiration was achieved by the addition of $0.5 \mathrm{mM}$ ADP. The hyperpolarization or depolarization of mitochondria was induced by $1 \mu \mathrm{M}$ oligomycin or $1 \mu \mathrm{M}$ m-CCCP addition, respectively. After an equilibration time, the fluorescence of the suspension was measured and the content of the cuvette was centrifuged at $15000 \mathrm{~g}$ to pellet mitochondria. The Rh-123 concentration remaining in the media ([Rh-123 $]_{\text {out }}$, in nmol $\left.\mu \mathrm{l}^{-1}\right)$ was calculated from the fluorescence values of the supernatant. The initial total amount of Rh-123 in the cuvette ([Rh-123] total $)$ and the amount remaining in the media ([Rh-123] out) were used to calculate by subtraction the total amount of Rh-123 taken up by mitochondria ([Rh-123 $]_{\text {mit }}$, in nmol per $\mathrm{mg}$ protein). The concentration of free Rh-123 in the matrix ([Rh-123] $]_{\text {in }}$, in nmol $\mu \mathrm{l}^{-1}$ ) was calculated using the following equation, and the bind- ing partition coefficients at $30{ }^{\circ} \mathrm{C}$ are $\left(K_{\mathrm{i}}=26 \mu \mathrm{lmg} \mathrm{mg}^{-1}\right.$, $\left.K_{\mathrm{o}}=120 \mu \mathrm{mg}^{-1}\right):^{61}$

$$
[\mathrm{Rh}-123]_{\text {mit }}=\mathrm{K}_{\underline{\mathrm{i}}}[\mathrm{Rh}-123]_{\mathrm{in}}+K_{\mathrm{o}}[\mathrm{Rh}-123]_{\mathrm{out}}
$$

Mitochondrial membrane potentials (negative inside) were calculated by using the electrochemical Nernst-Guggenheim equation: $\Delta \Psi=59 \log \left([\mathrm{Rh}-123]_{\text {in }} /[\mathrm{Rh}-123]_{\text {out }}\right)$.

\section{Mitochondrial hydrogen peroxide production}

Mitochondrial $\mathrm{H}_{2} \mathrm{O}_{2}$ production was performed fluorometrically at $365-450 \mathrm{~nm}\left(\lambda_{\text {exc-em }}\right)$, at $30{ }^{\circ} \mathrm{C}$, through the scopoletinhorseradish peroxidase (HRP) assay, ${ }^{62}$ using a Hitachi F-3010 fluorescence spectrophotometer. The reaction medium consisted of $230 \mathrm{mM}$ mannitol, $70 \mathrm{mM}$ sucrose, and $20 \mathrm{mM}$ Tris$\mathrm{HCl}$, pH 7.40, added with $0.5 \mu \mathrm{M} \mathrm{Cu}, \mathrm{Zn}-\mathrm{SOD}, 1 \mu \mathrm{M}$ HRP, $1 \mu \mathrm{M}$ scopoletin and coupled mitochondrial suspensions (0.10-0.30 $\mathrm{mg}$ protein per $\mathrm{ml}$ ) pre-incubated for $2 \mathrm{~min}$ in the absence or in the presence of 1-100 nM (+)-catechin. Mitochondrial $\mathrm{H}_{2} \mathrm{O}_{2}$ production rates were tested in state 4 using $6 \mathrm{mM}$ malate and $6 \mathrm{mM}$ glutamate as complex I substrates. A calibration curve was recorded using $\mathrm{H}_{2} \mathrm{O}_{2}$ $(0.05-0.35 \mu \mathrm{M})$ as the standard, previously titrated spectrophotometrically at $240 \mathrm{~nm}\left(\varepsilon=43.6 \mathrm{M}^{-1} \mathrm{~cm}^{-1}\right)$ to express the fluorescence changes as nmol $\mathrm{H}_{2} \mathrm{O}_{2}$ per min per $\mathrm{mg}$ protein.

\section{Protein concentration and statistics}

Protein concentration was determined with the Folin reagent ${ }^{63}$ using bovine serum albumin as the standard. Results included in tables and figures are expressed as means \pm SEM of four or five independent experiments. Dunnet's t test was used to analyze the significance of differences between paired determinations. The 0.01 or 0.05 probability levels were used as a criterion for biological significance. Statistical analysis was performed using GraphPad Instat4 (GraphPad Software, La Jolla, CA, USA).

\section{Results}

\section{Mitochondrial complex I activity}

The effect of (+)-catechin on mitochondrial complex I was studied measuring $\mathrm{NADH}-\mathrm{Q}_{1}$ reductase (complex I) and $\mathrm{NADH}$-cytochrome c reductase (complex I-III) activities (Fig. 1). NADH- $\mathrm{Q}_{1}$ reductase activity was $25 \%$ inhibited by the addition of $10 \mathrm{nM}(+)$-catechin to the reaction medium. The maximal inhibitory effect of this polyphenol on $\mathrm{NADH}-\mathrm{Q}_{1}$ reductase activity was observed at $100 \mu \mathrm{M}(+)$-catechin; under this experimental condition, only $50 \%$ of complex I activity has been detected. As it was expected, the addition of $1 \mu \mathrm{M}$ rotenone produced the almost complete (>95\%) inhibition of complex I activity (data not shown). Taking into account that cytochrome $\mathrm{c}$ is a molecular target of flavonoids, ${ }^{64} \mathrm{NADH}-\mathrm{cyto}-$ chrome c activity could not be an adequate technique to study the in vitro effect of $(+)$-catechin on complex I activity. Despite the fact that the inhibitory effect was not statistically significant and was less noticeable than when $\mathrm{NADH}-\mathrm{Q}_{1}$ reductase 


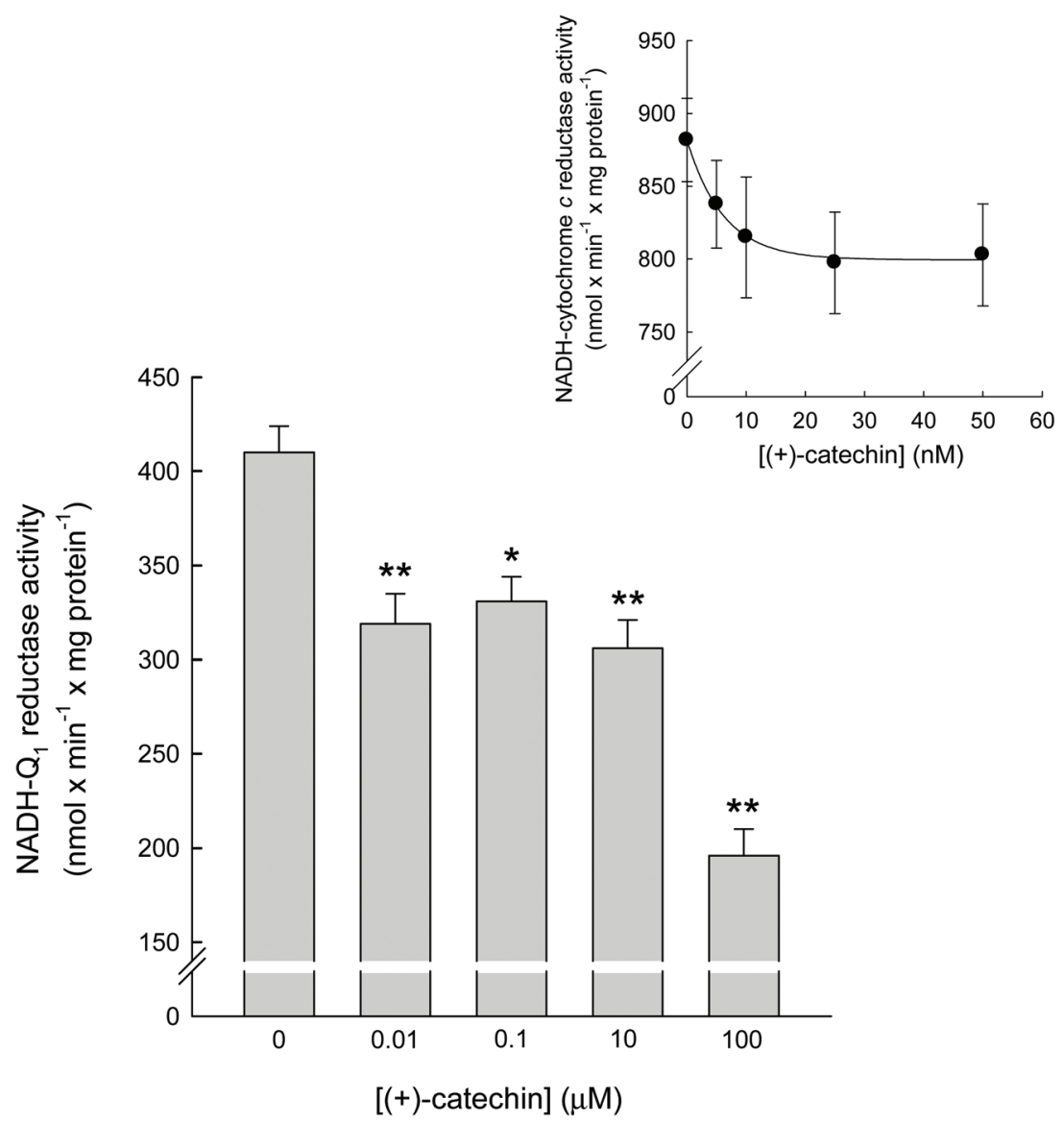

Fig. 1 Effect of (+)-catechin on mitochondrial complex I. NADH-Q 1 reductase (complex I) and NADH-cytochrome c reductase (complex I-III; inset) activities as a function of $(+)$-catechin concentration. Results are expressed as mean \pm SEM of 5 independent experiments. ${ }^{*} p<0.05$, ${ }^{* *} p<$ 0.01 in the presence vs. in the absence of $(+)$-catechin.

activity was measured, the influence of the addition of $\mathrm{nM}$ concentrations of $(+)$-catechin was also observed when complex I-III activity was measured (Fig. 1 inset): NADH-cytochrome c reductase activity was $10 \%$ reduced by $25 \mathrm{nM}$ (+)-catechin.

Thus, in the $\mathrm{nM}$ range, (+)-catechin inhibited complex I measured not only by the NADH- $\mathrm{Q}_{1}$ reductase assay but also by the NADH-cytochrome c reductase technique, suggesting an action of this flavan-3-ol on the complex I structure.

\section{Mitochondrial membrane potential}

In order to evaluate the effect of mitochondrial complex I inhibition by $(+)$-catechin on mitochondrial membrane potential $(\Delta \Psi)$, the fluorescence changes associated with Rh-123 distribution were measured in the absence or in the presence of 10 $\mathrm{nM}$ to $5 \mu \mathrm{M}(+)$-catechin, using malate-glutamate as the substrate of complex I (Fig. 2). In the nM range, $(+)$-catechin decreased state $4 \Delta \Psi$ (Fig. 2A) but failed to change the membrane potential measured in the presence of ADP (state 3; Fig. 2B). The membrane potential corresponding to state 4 respiration was reduced in $10 \mathrm{mV}$ when mitochondria were exposed to $10 \mathrm{nM}(+)$-catechin. Although these changes were not statistically significant, the shift observed towards lower membrane potentials is highly relevant under physiological conditions. The physiological mitochondrial $\Delta \Psi$ is in a narrow range, between 150 (state 3) and $175 \mathrm{mV}$ (state 4), where small changes in the potential are causative of depolarization. Thus, the difference in the membrane potential of mitochondria moving from a state 4 to a state 3 is not higher than 15-25 mV. ${ }^{32}$ Membrane potential values detected during resting respiration, in the presence of $100 \mathrm{nM}$ or $5 \mu \mathrm{M}(+)$-catechin, were similar to the one registered in the presence of 10 $\mathrm{nM}$ of this polyphenol, suggesting that this membrane potential-inhibition degree is the highest effect of this compound under the assayed experimental conditions. This observation is in agreement with the uncoupling effect exerted by classical uncoupling agents, such as FCCP or mCCCP. ${ }^{5}$

\section{Hydrogen peroxide and nitric oxide production rates}

Considering that complex I produces $\mathrm{O}_{2}{ }^{-}$, the stoichiometric precursor of $\mathrm{H}_{2} \mathrm{O}_{2}$, the effect of (+)-catechin on mitochondrial production of this latter species was measured using malateglutamate as the complex I substrate. (+)-Catechin reduced state 4 mitochondrial $\mathrm{H}_{2} \mathrm{O}_{2}$ production (Fig. $3 \mathrm{~A}$ ) in a concentration dependent manner. At $10 \mathrm{nM}(+)$-catechin, the $\mathrm{H}_{2} \mathrm{O}_{2}$ production rate was reduced by $35 \%$. The supplementation of 

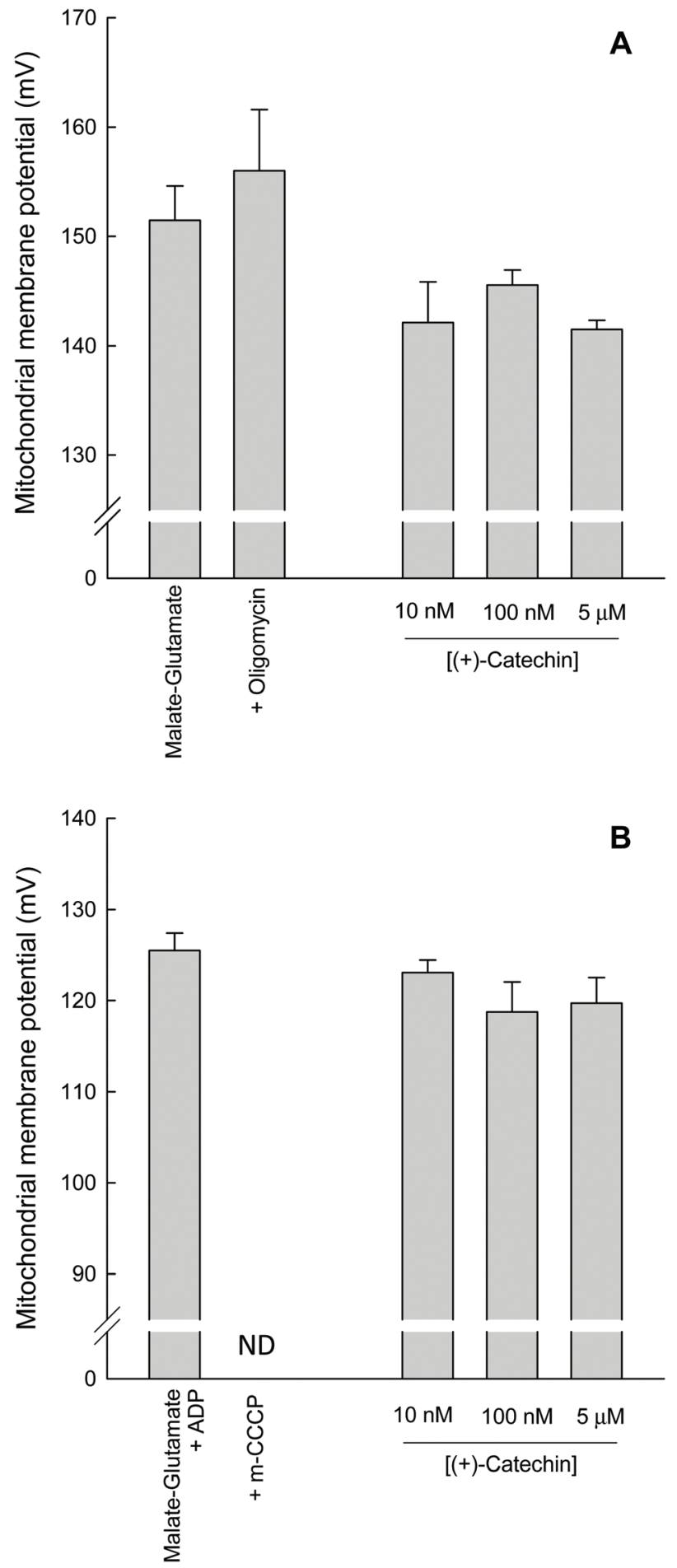

Fig. 2 Effect of $(+)$-catechin on mitochondrial membrane potential $(\Delta \Psi)$ of mitochondria energized by malate-glutamate in the absence (A) and in the presence (B) of ADP. Hyperpolarization or depolarization of mitochondria was induced by $1 \mu \mathrm{M}$ oligomycin or $1 \mu \mathrm{M} \mathrm{m}$-CCCP addition, respectively, and was included as controls. Results are expressed as mean \pm SEM of 5 independent experiments. ND: not detectable. the reaction medium with $1 \mu \mathrm{M}$ rotenone produced an enhancement in the $\mathrm{H}_{2} \mathrm{O}_{2}$ production rate of about $50 \%$ $(0.72 \pm 0.03 \mathrm{nmol}$ per min per $\mathrm{mg}$ protein). When the mitochondrial suspension was pre-incubated in the presence of $5 \mu \mathrm{M}(+)$-catechin, $\mathrm{H}_{2} \mathrm{O}_{2}$ production was decreased by $40 \%$, the same reduction degree that has been detected in the presence of $100 \mathrm{nM}(+)$-catechin, indicating that the inhibition observed at $100 \mathrm{nM}$ was the maximal in vitro effect of (+)-catechin on $\mathrm{H}_{2} \mathrm{O}_{2}$ generation.

Taking into account the reported functional interaction between complex I and mtNOS activities, ${ }^{28,31}$ and the regulation of mitochondrial NO production by membrane potential, ${ }^{30,32,33}$ mtNOS activity was measured and the effect of 1.0-25 $\mathrm{nM}(+)$-catechin was studied. This concentration range was selected according to the effects of that flavonoid on complex I activity and mitochondrial membrane potential. Fig. 3B shows that $(+)$-catechin inhibited NO production of heart mitochondrial membranes in a concentration dependent manner. Mitochondrial NOS activity showed a hyperbolic decay as a function of (+)-catechin concentration. At $10 \mathrm{nM}$ (+)-catechin, a decline of about $50 \%$ in mitochondrial NO production was observed.

In addition, NO production by rat recombinant nNOS was assayed in an attempt to study the effect of $(+)$-catechin on the NOS structure. Table 1 shows that NO production was inhibited when nNOS activity was evaluated in the presence of 3 or $10 \mathrm{nM}(+)$-catechin, suggesting a direct action of this flavonoid on the enzyme structure. At $10 \mathrm{nM}(+)$-catechin, the recombinant nNOS activity was $45 \%$ decreased.

Moreover, considering the results obtained in the presence of $(+)$-catechin concentrations lower than $10 \mathrm{nM}$, linear and positive correlations were obtained (Fig. 3C) between mitochondrial NADH-Q $\mathrm{Q}_{1}$ reductase activity and $\mathrm{H}_{2} \mathrm{O}_{2}$ production rate $\left(r^{2}=0.958\right)$ and between $\mathrm{NADH}-\mathrm{Q}_{1}$ reductase and mtNOS activities $\left(r^{2}=0.973\right)$, suggesting a functional association among these mitochondrial parameters.

\section{Discussion}

It has been reported that flavonoids can exert effects not only through antioxidant but also by non-antioxidant mechanisms, which can be combined to protect the cell against injury. Thus, flavonoids can act by virtue of their free radical scavenging properties, their transition metal-chelating abilities or by enzymatic activities modulation. ${ }^{65,66}$ In the present work, the addition of $\mathrm{nM}$ concentrations of $(+)$-catechin to the reaction medium inhibited not only mitochondrial complex I activity (Fig. 1) but also the $\mathrm{H}_{2} \mathrm{O}_{2}$ production rate sustained by malateglutamate (Fig. 3A), in accordance with the decrease observed in mitochondrial membrane potential (Fig. 2). These results agree with the finding of Lagoa et al. ${ }^{64}$ who have shown that quercetin and kaempferol inhibit rotenone-sensitive $\mathrm{NADH}: \mathrm{Q}_{1}$ oxidoreductase activity in submitochondrial particles and the $\mathrm{H}_{2} \mathrm{O}_{2}$ production sustained by this complex, in rat brain mitochondria. These authors argue that the inhi- 


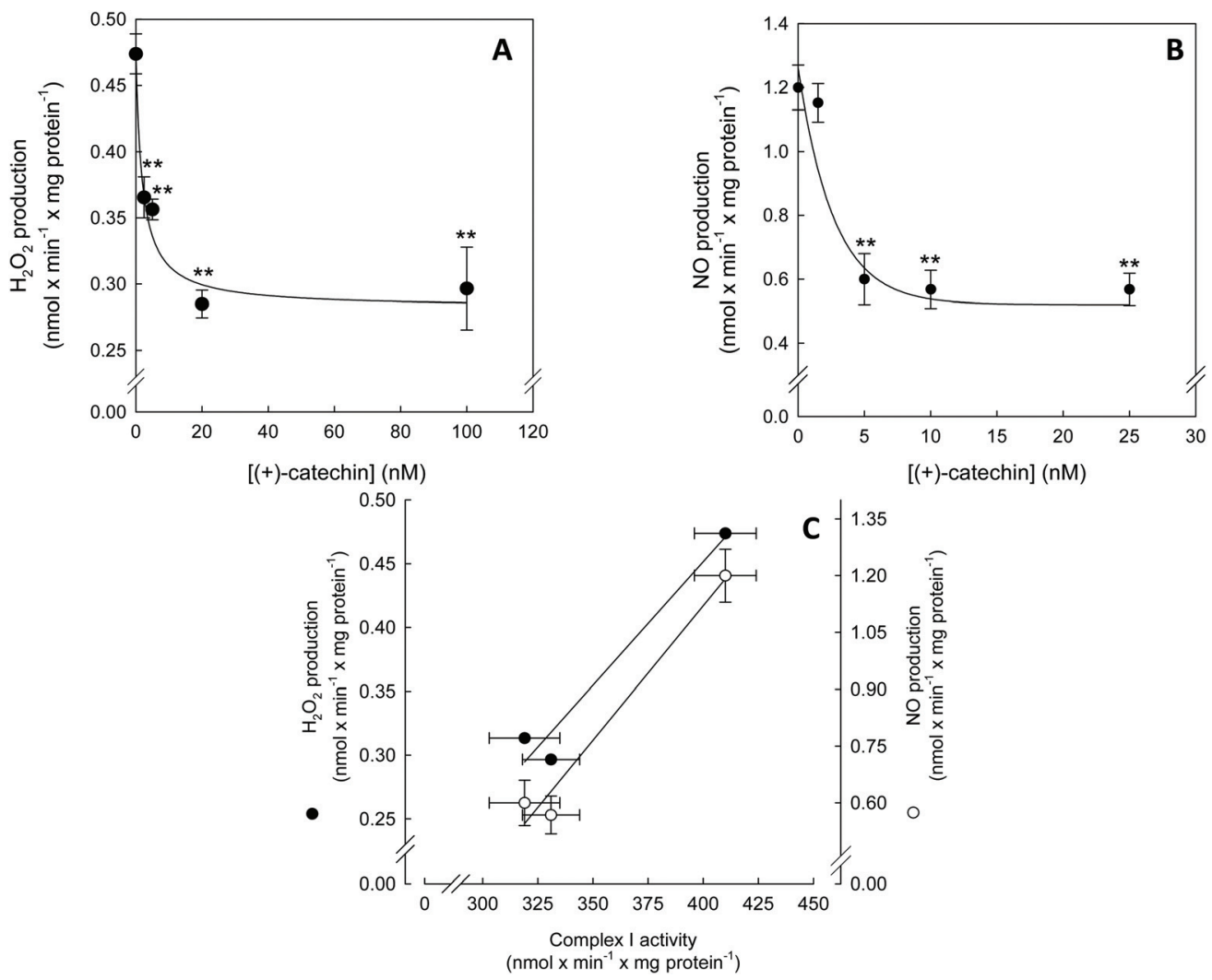

Fig. 3 Effect of (+)-catechin on mitochondrial $\mathrm{H}_{2} \mathrm{O}_{2}(A)$ and $\mathrm{NO}(B)$ production rates. Linear correlations between complex I and mtNOS activities (open circles), or complex I activity and $\mathrm{H}_{2} \mathrm{O}_{2}$ production rate (closed circles) (C) considering [(+)-catechin] concentration to be lower than 10 nM. Results are expressed as mean \pm SEM of 5 independent experiments. ${ }^{* *} p<0.01$ in the presence vs. in the absence of $(+)$-catechin.

Table 1 Effect of $(+)$-catechin on NO production sustained by recombinant nNOS activity

\begin{tabular}{cc}
\hline $\begin{array}{c}(+)-C a t e c h i n] \\
(\mathrm{nM})\end{array}$ & $\begin{array}{c}\text { nNOS activity } \\
\left(\mathrm{nmol} \mathrm{NO} \mathrm{min}^{-1} \mathrm{U}^{-1}\right)\end{array}$ \\
\hline 0.0 & $1.30 \pm 0.10$ \\
3.0 & $0.67 \pm 0.05^{* *}$ \\
10 & $0.71 \pm 0.07^{* *}$
\end{tabular}

Results are expressed as mean \pm SEM of 4 independent experiments. ${ }^{* *} p<0.01$ in the presence $v s$. in the absence of $(+)$-catechin.

bition of complex I activity depends on the concentration of ubiquinone added to the medium, suggesting that quercetin and kaempherol affect the binding of the coenzyme to the enzyme. ${ }^{64}$ The inhibition of the electron transfer chain at complex I by kaempferol was also reported by Filomeni et al., ${ }^{67}$ who have shown that the pre-treatment of HeLa cells with $200 \mu \mathrm{M}$ kaempferol inhibited malate-glutamate supported respiration, whereas no significant effect was observed in succinate supported respiration.

As a consequence of the inhibition of complex I activity exerted by $(+)$-catechin, the proton pumping by this complex could be affected, explaining the registered $\Delta \Psi$ reduction. It is important to point out that the state $4 \Delta \Psi$ was $10 \mathrm{mV}$ lower in the presence of the flavonoid than in its absence. According to
Gerencser et al. ${ }^{68}$ this difference in the voltage value implies a 2 -fold reduction in the maximal rate of mitochondrial ATP production in isolated mitochondria. In addition, it is known that the mitochondrial $\mathrm{O}_{2}{ }^{-}$production rate, i.e. of the stoichiometric precursor of mitochondrial $\mathrm{H}_{2} \mathrm{O}_{2}$, depends not only on the reduction degree of the components of the respiratory chain but also on the mitochondrial membrane potential. ${ }^{8,10}$ It was recognized that ionophores, protophores and compounds that collapse $\Delta \Psi$ regulate the rates of $\mathrm{H}_{2} \mathrm{O}_{2}$ production..$^{8,10,54,69,70}$ Korshunov et al. ${ }^{69}$ reported a hyperbolic relationship between membrane potential and $\mathrm{H}_{2} \mathrm{O}_{2}$ production in rat heart mitochondria with a threshold value that exceeds the state $3 \Delta \Psi$ level, above which a very strong increase in $\mathrm{H}_{2} \mathrm{O}_{2}$ production takes place. Hansford et al. ${ }^{71}$ showed that active $\mathrm{H}_{2} \mathrm{O}_{2}$ production by heart mitochondria requires both a high fractional reduction of complex I and a high membrane potential. According to Skulachev, ${ }^{72}$ a slight uncoupling of mitochondrial respiration leads to a moderate decrease in membrane potential, preventing $\mathrm{O}_{2}{ }^{-}$and consequently $\mathrm{H}_{2} \mathrm{O}_{2}$ generation. Thus, $\mathrm{nM}$ concentrations of $(+)$-catechin could lead to a mild uncoupling of mitochondrial respiration sustained by substrates of complex I, the latter, the major entry point for electrons from NADH produced by the tricarboxylic acid cycle.

In addition, (+)-catechin inhibited NO production sustained by mtNOS. In the nM range, mtNOS activity showed a hyper- 
bolic decay as a function of (+)-catechin concentration (Fig. 3B). Furthermore, when the effect of $10 \mathrm{nM}(+)$-catechin was tested on NO production catalyzed by recombinant nNOS, as a prototype of the NOS isoform located in mitochondria, ${ }^{12}$ that flavonoid produced a decrease of about $45 \%$ in NO generation, suggesting that (+)-catechin could inhibit mtNOS activity through a direct action on the enzyme structure. Taking into account the quantity and the activity of the recombinant nNOS used (Table 1), it is possible to estimate the ratio between the concentration of the $(+)$-catechin added (3-10 nM) and the concentration of the pure enzyme. Accordingly, considering $200 \mathrm{U}$ per $\mathrm{mg}$ protein from the data sheet of rat recombinant nNOS (N3033, Sigma Chemical Co.), and the maximal concentration of nNOS used under the assayed conditions, i.e. $0.18 \mathrm{U}$ nNOS per $\mathrm{ml}$, and $300000 \mathrm{~g} \mathrm{~mol}^{-1}$ as $\mathrm{MW}$ of nNOS, the estimated concentration of nNOS in the reaction medium is $\sim 3 \mathrm{nM}$. In this situation, the ratio $(+)$-catechin : recombinant nNOS is about $1: 1$. Therefore, the enzyme mtNOS is probably saturated when the effect of 1 to $25 \mathrm{nM}$ $(+)$-catechin on NO production by heart mitochondria (nmol NO per min per mg total mitocondrial protein) is evaluated, because of that under this experimental condition the specific amount of mtNOS is expected to be lower than the quantity of recombinant NOS. This fact could explain why higher concentrations of $(+)$-catechin do not produce a greater inhibitory effect on mtNOS activity.

The combined decline in $\mathrm{H}_{2} \mathrm{O}_{2}$ and NO production rates is in agreement with the reported functional interaction between complex I and mtNOS proteins ${ }^{22,23,29,31}$ and with the results obtained by Franco et al. ${ }^{28}$ who have shown that complex I proteins from rat liver mitochondria co-immunoprecipitate with mtNOS. Moreover, data from our laboratory have shown that heart mitochondrial inside-out particles produce NO supported by succinate-dependent reversed electron flow in the respiratory chain, emphasizing the notion that mtNOS and complex I proteins are functionally associated ${ }^{31}$ and contiguously located. The mtNOS and complex I association is compatible not only with the concept of respiratory chain supercomplex formation with strong protein-protein interactions, ${ }^{73,74}$ but also with the dependence of mtNOS activity on the metabolic states and membrane potential. We have previously shown that mitochondrial NO production exponentially depends on mitochondrial membrane potential; ${ }^{30,32,33}$ and this dependence is more pronounced in the physiological range of membrane potential (150-175 mV), where small changes in the $\Delta \Psi$ produce noticeable variations of mitochondrial NO release. Several studies have shown that abolishing $\Delta \Psi$ inhibits NO production by mtNOS activity, suggesting a tight regulatory interplay between mitochondrial membrane potential and NO production..$^{32,33,75}$ Therefore, in coupled mitochondria, the fall in $\Delta \Psi$ due to the addition of (+)-catechin could lead not only to the decrease in $\mathrm{H}_{2} \mathrm{O}_{2}$ production but also in NO generation by mtNOS.

Despite the emerging interest in the beneficial actions of polyphenols over mitochondria, there is little information regarding bioavailability and internalization of these bioactive

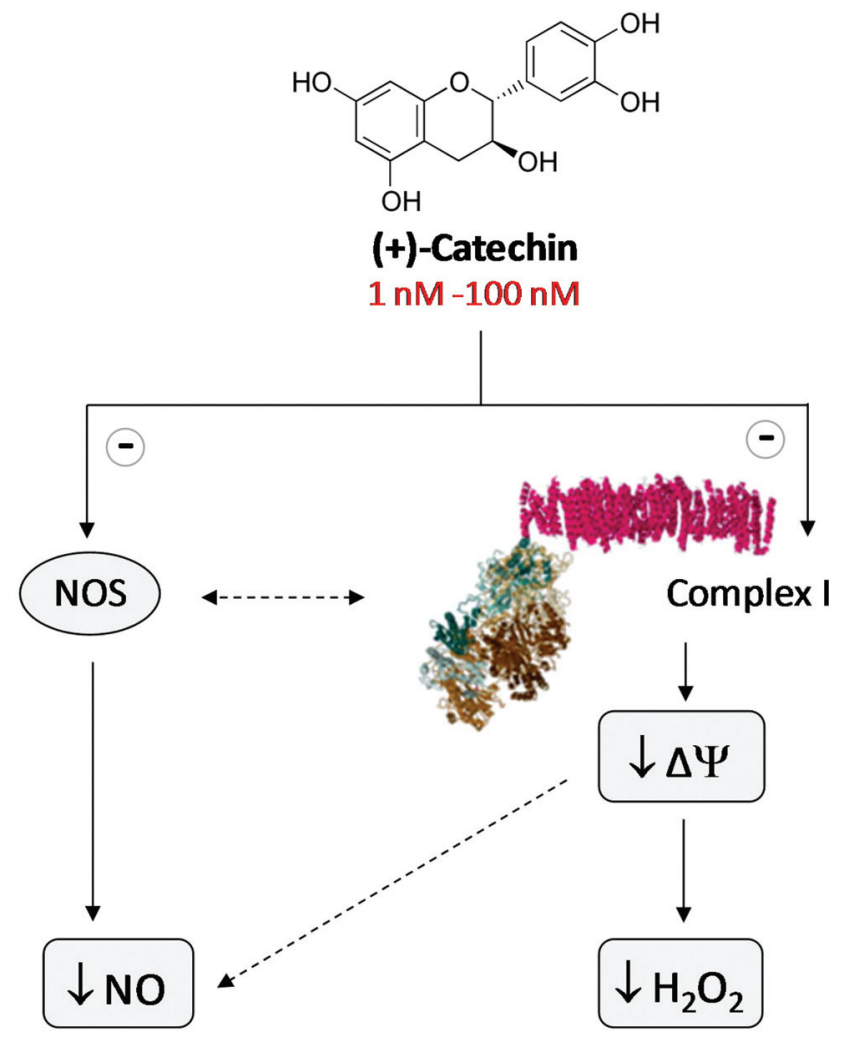

Fig. 4 Schematic representation showing the in vitro effects of $n M$ to low $\mu \mathrm{M}$ concentrations of $(+)$-catechin on mitochondrial complex I activity, membrane potential $(\Delta \Psi)$ and $\mathrm{H}_{2} \mathrm{O}_{2}$ and $\mathrm{NO}$ productions. Straight lines indicate pathways supported by the results included in this work and dotted lines suggest pathways reported by bibliography.

compounds by the organelles. However, it has been shown that flavonoids can accumulate in mitochondria. ${ }^{36,37,76}$ According to Stevens et al. ${ }^{77}$ the physicochemical properties of polyphenols, such as lipophilicity and $\mathrm{p} K_{\mathrm{a}}$, actually favor their enrichment in mitochondria. Since $(+)$-catechin has favorable $\mathrm{p} K_{\mathrm{a} 1}(8.68 \pm 0.23)$, close to the physiological $\mathrm{pH}$ of the cytosol and mitochondrial compartments, and distribution coefficient $(\log P=0.61)$, it would able to reach the mitochondrial matrix and exert its biological effects within the organelle. According to our results, (+)-catechin, in the $\mathrm{nM}$ concentration range, inhibits mitochondrial complex I activity leading to a membrane potential decrease and consequently to $\mathrm{H}_{2} \mathrm{O}_{2}$ production reduction. The decrease in mitochondrial NO generation could be a consequence of the direct action of $(+)$-catechin on the NOS structure, and also correlates with the functional interaction between complex I and mtNOS and the dependence of mtNOS activity on $\Delta \Psi$ (Fig. 4).

\section{Conclusion}

Physiologically relevant concentrations of $(+)$-catechin could modulate the mitochondrial redox state and the generation of signaling molecules, such as $\mathrm{H}_{2} \mathrm{O}_{2}$ and NO, through non-anti- 
oxidant mechanisms. In this context, the mitochondrial enzymes complex I and mtNOS would be the direct targets of that flavonoid.

\section{Abbreviations}

$\mathrm{H}_{2} \mathrm{O}_{2} \quad$ Hydrogen peroxide

mtNOS Mitochondrial nitric oxide synthase

NO Nitric oxide

$\Delta \Psi \quad$ Mitochondrial membrane potential

\section{Conflicts of interest}

There are no conflicts to declare.

\section{Acknowledgements}

This work was supported by research grants from the University of Buenos Aires (UBACyT 200-201-101-00140BA, and 200-201-301-00731BA), Agencia Nacional de Promoción Científica y Tecnológica (ANPCyT, PICT 2008-1138 and 20120964), and Consejo Nacional de Investigaciones Científicas y Técnicas (PIP 112-200-801-00688 and PIP 112-201-101-00444).

\section{References}

1 J. E. Walker, The NADH:ubiquinone oxidoreductase (complex I) of respiratory chains, Q. Rev. Biophys., 1992, 25, 253-324.

2 V. Zickermann, C. Wirth, H. Nasiri, K. Siegmund, H. Schwalbe, C. Hunte and U. Brandt, Structural biology. Mechanistic insight from the crystal structure of mitochondrial complex I, Science, 2015, 347, 44-49.

3 A. J. Jones, J. N. Blaza, F. Varghese and J. Hirst, Respiratory Complex $\mathrm{I}$ in Bos taurus and Paracoccus denitrificans Pumps Four Protons across the Membrane for Every NADH Oxidized, J. Biol. Chem., 2017, 292, 4987-4995.

4 E. Cadenas, A. Boveris, C. I. Ragan and A. O. Stoppani, Production of superoxide radicals and hydrogen peroxide by NADH-ubiquinone reductase and ubiquinol-cytochrome c reductase from beef-heart mitochondria, Arch. Biochem. Biophys., 1977, 180, 248-257.

5 J. F. Turrens and A. Boveris, Generation of superoxide anion by the NADH dehydrogenase of bovine heart mitochondria, Biochem. J., 1980, 191, 421-427.

6 K. R. Pryde and J. Hirst, Superoxide is produced by the reduced flavin in mitochondrial complex I: a single, unified mechanism that applies during both forward and reverse electron transfer, J. Biol. Chem., 2011, 286, 1805618065.

7 S. T. Ohnishi, T. Ohnishi, S. Muranaka, H. Fujita, H. Kimura, K. Uemura, K. Yoshida and K. Utsumi, A possible site of superoxide generation in the complex I segment of rat heart mitochondria, J. Bioenerg. Biomembr., 2005, 37, 1-15.
8 A. Boveris, N. Oshino and B. Chance, The cellular production of hydrogen peroxide, Biochem. J., 1972, 128, 617-630.

9 R. A. Weisiger and I. Fridovich, Mitochondrial superoxide dismutase. Site of synthesis and intramitochondrial localization, J. Biol. Chem., 1973, 248, 4793-4796.

10 A. Boveris and B. Chance, The mitochondrial generation of hydrogen peroxide. General properties and effect of hyperbaric oxygen, Biochem. J., 1973, 134, 707-716.

11 A. Boveris and E. Cadenas, Mitochondrial production of hydrogen peroxide regulation by nitric oxide and the role of ubisemiquinone, IUBMB Life, 2000, 50, 245-250.

12 A. Tatoyan and C. Giulivi, Purification and characterization of a nitric-oxide synthase from rat liver mitochondria, J. Biol. Chem., 1998, 273, 11044-11048.

13 C. Giulivi, J. J. Poderoso and A. Boveris, Production of nitric oxide by mitochondria, J. Biol. Chem., 1998, 273, 11038-11043.

14 S. L. Elfering, T. M. Sarkela and C. Giulivi, Biochemistry of mitochondrial nitric-oxide synthase, J. Biol. Chem., 2002, 277, 38079-38086.

15 L. B. Valdez, S. Alvarez, S. L. Arnaiz, F. Schopfer, M. C. Carreras, J. J. Poderoso and A. Boveris, Reactions of peroxynitrite in the mitochondrial matrix, Free Radicals Biol. Med., 2000, 29, 349-356.

16 L. B. Valdez, S. S. Bombicino, D. E. Iglesias, I. Rukavina Mikusic and A. Boveris, Mitochondrial peroxynitrite generation is mainly driven by superoxide steady-state concentration rather than by nitric oxide steady-state concentration, Int. J. Mol. Biol. Open Access, 2018, 3, 58-63.

17 S. Bartesaghi and R. Radi, Fundamentals on the biochemistry of peroxynitrite and protein tyrosine nitration, Redox Biol., 2018, 14, 618-625.

18 A. Navarro and A. Boveris, Brain mitochondrial dysfunction and oxidative damage in Parkinson's disease, J. Bioenerg. Biomembr., 2009, 41, 517-521.

19 A. Navarro, A. Boveris, M. J. Bandez, M. J. Sanchez-Pino, C. Gomez, G. Muntane and I. Ferrer, Human brain cortex: mitochondrial oxidative damage and adaptive response in Parkinson disease and in dementia with Lewy bodies, Free Radicals Biol. Med., 2009, 46, 1574-1580.

20 L. B. Valdez, M. J. Bández, A. Navarro and A. Boveris, in Etiology and Pathophysiology of Parkinson's disease, ed. A. Q. Ranna, InTech, Croatia, 2011, ch. 14, pp. 317-328.

21 F. Yin, A. Boveris and E. Cadenas, Mitochondrial energy metabolism and redox signaling in brain aging and neurodegeneration, Antioxid. Redox Signaling, 2014, 20, 353-371.

22 L. B. Valdez, T. Zaobornyj, S. Bombicino, D. E. Iglesias, A. Boveris, M. Donato, V. D'Annunzio, B. Buchholz and R. J. Gelpi, Complex I syndrome in myocardial stunning and the effect of adenosine, Free Radicals Biol. Med., 2011, 51, 1203-1212.

23 L. B. Valdez, S. S. Bombicino, D. E. Iglesias, I. A. RukavinaMikusic and V. D'Annunzio, in Biochemistry of oxidative stress. Physiopathology and clinical aspects, ed. R. J. Gelpi, A. Boveris and J. J. Poderoso, Springer, New York, 2016, ch. 16, pp. 245-257. 
24 V. Vanasco, N. D. Magnani, M. C. Cimolai, L. B. Valdez, P. Evelson, A. Boveris and S. Alvarez, Endotoxemia impairs heart mitochondrial function by decreasing electron transfer, ATP synthesis and ATP content without affecting membrane potential, J. Bioenerg. Biomembr., 2012, 44, 243-252.

25 L. B. Valdez, T. Zaobornyj, S. Alvarez, J. Bustamante, L. E. Costa and A. Boveris, Heart mitochondrial nitric oxide synthase. Effects of hypoxia and aging, Mol. Aspects Med., 2004, 25, 49-59.

26 A. Navarro and A. Boveris, Rat brain and liver mitochondria develop oxidative stress and lose enzymatic activities on aging, Am. J. Physiol.: Regul., Integr. Comp. Physiol., 2004, 287, 1244-1249.

27 A. Navarro and A. Boveris, Brain mitochondrial dysfunction in aging, neurodegeneration, and Parkinson's disease, Front. Aging Neurosci., 2010, 2, 34.

28 M. C. Franco, V. G. Arciuch, J. G. Peralta, S. Galli, D. Levisman, L. M. Lopez, L. Romorini, J. J. Poderoso and M. C. Carreras, Hypothyroid phenotype is contributed by mitochondrial complex I inactivation due to translocated neuronal nitric-oxide synthase, J. Biol. Chem., 2006, 281, 4779-4786.

29 M. S. Parihar, R. R. Nazarewicz, E. Kincaid, U. Bringold and P. Ghafourifar, Association of mitochondrial nitric oxide synthase activity with respiratory chain complex I, Biochem. Biophys. Res. Commun., 2008, 366, 23-28.

30 L. B. Valdez and A. Boveris, Mitochondrial nitric oxide synthase, a voltage-dependent enzyme, is responsible for nitric oxide diffusion to cytosol, Front. Biosci., 2007, 12, 1210-1219.

31 S. S. Bombicino, D. E. Iglesias, T. Zaobornyj, A. Boveris and L. B. Valdez, Mitochondrial nitric oxide production supported by reverse electron transfer, Arch. Biochem. Biophys., 2016, 607, 8-19.

32 L. B. Valdez, T. Zaobornyj and A. Boveris, Mitochondrial metabolic states and membrane potential modulate mtNOS activity, Biochim. Biophys. Acta, 2006, 1757, 166172.

33 A. Boveris, L. B. Valdez, T. Zaobornyj and J. Bustamante, Mitochondrial metabolic states regulate nitric oxide and hydrogen peroxide diffusion to the cytosol, Biochim. Biophys. Acta, 2006, 1757, 535-542.

34 C. Sandoval-Acuña, J. Ferreira and H. Speisky, Polyphenols and mitochondria: an update on their increasingly emerging ROS-scavenging independent actions, Arch. Biochem. Biophys., 2014, 559, 75-90.

35 J. Teixeira, D. Chavarria, F. Borges, L. Wojtczak, M. R. Wieckowski, A. Karkucińska-Wieckowska and P. J. Oliveira, Dietary polyphenols and mitochondrial function: role in health and disease, Curr. Med. Chem., 2017, DOI: 10.2174/0929867324666170529101810.

36 E. K. Schroeder, N. A. Kelsey, J. Doyle, E. Breed, R. J. Bouchard, F. A. Loucks, R. A. Harbison and D. A. Linseman, Green tea epigallocatechin 3-gallate accumulates in mitochondria and displays a selective antiapoptotic effect against inducers of mitochondrial oxidative stress in neurons, Antioxid. Redox Signaling, 2009, 11, 469480.

37 M. Fiorani, A. Guidarelli, M. Blasa, C. Azzolini, M. Candiracci, E. Piatti and O. Cantoni, Mitochondria accumulate large amounts of quercetin: prevention of mitochondrial damage and release upon oxidation of the extramitochondrial fraction of the flavonoid, J. Nutr. Biochem., 2010, 21, 397-404.

38 W. Bors, C. Michel and M. Saran, Flavonoid antioxidants: rate constants for reactions with oxygen radicals, Methods Enzymol., 1994, 234, 420-429.

39 G. Sichel, C. Corsaro, M. Scalia, A. J. Di Bilio and R. P. Bonomo, In vitro scavenger activity of some flavonoids and melanin against $\mathrm{O}_{2}{ }^{-}$, Free Radicals Biol. Med., 1991, 11, 1-8.

40 G. R. Haenen and A. Bast, Nitric oxide radical scavenging of flavonoids, Methods Enzymol., 1999, 301, 490-503.

41 K. Ishige, D. Schubert and Y. Sagara, Flavonoids protect neuronal cells from oxidative stress by three distinct mechanisms, Free Radicals Biol. Med., 2001, 30, 433446.

42 G. Williamson and C. Manach, Bioavailability and bioefficacy of polyphenols in humans. II. Review of 93 intervention studies, Am. J. Clin. Nutr., 2005, 81, 243S-255S.

43 C. Manach, G. Williamson, C. Morand, A. Scalbert and C. Rémésy, Bioavailability and bioefficacy of polyphenols in humans. I. Review of 97 bioavailability studies, Am. J. Clin. Nutr., 2005, 81, 230S-242S.

44 S. Mandel, L. Reznichenko, T. Amit and M. B. Youdim, Green tea polyphenol (-)-epigallocatechin-3-gallate protects rat PC12 cells from apoptosis induced by serum withdrawal independent of P13-Akt pathway, Neurotoxic. Res., 2003, 5, 419-424.

45 S. Mandel, T. Amit, L. Reznichenko, O. Weinreb and M. B. Youdim, Green tea catechins as brain-permeable, natural iron chelators-antioxidants for the treatment of neurodegenerative disorders, Mol. Nutr. Food Res., 2006, 50, 229-234.

46 C. G. Fraga, P. I. Oteiza and M. Galleano, Plant bioactives and redox signaling: (-)-Epicatechin as a paradigm, Mol. Aspects Med., 2018, 61, 31-40.

47 Y. Steffen, C. Gruber, T. Schewe and H. Sies, Mono-Omethylated flavanols and other flavonoids as inhibitors of endothelial NADPH oxidase, Arch. Biochem. Biophys., 2008, 469, 209-219.

48 M. C. Litterio, M. A. Vazquez Prieto, A. M. Adamo, R. Elesgaray, P. I. Oteiza, M. Galleano and C. G. Fraga, (-)-Epicatechin reduces blood pressure increase in highfructose-fed rats: effects on the determinants of nitric oxide bioavailability, J. Nutr. Biochem., 2015, 26, 745751.

49 P. Cos, L. Ying, M. Calomme, J. P. Hu, K. Cimanga, B. Van Poel, L. Pieter, A. J. Vlietinck and D. Vanden Berghe, Structure-activity relationship and classification of flavonoids as inhibitors of xanthine oxidase and superoxide scavengers, J. Nat. Prod., 1998, 61, 71-76. 
50 M. J. Laughton, P. J. Evans, M. A. Moroney, J. R. S. Hoult and B. Halliwell, Inhibition of mammalian 5-lipoxygenase and cyclo-oxygenase by flavonoids and phenolic dietary additives: relationship to antioxidant activity and to iron ion-reducing ability, Biochem. Pharmacol., 1991, 42, 1673-1681.

51 C. Gutierrez-Merino, C. Lopez-Sanchez, R. Lagoa, A. K. Samhan-Arias, C. Bueno and V. Garcia-Martinez, Neuroprotective actions of flavonoids, Curr. Med. Chem., 2011, 18, 1195-1212.

52 W. T. Chang, Z. H. Shao, J. J. Yin, S. Mehendale, C. Z. Wang, Y. Qin, J. Li, W. J. Chen, C. T. Chien, L. B. Becker, T. L. Vanden Hoek and C. S. Yuan, Comparative effects of flavonoids on oxidant scavenging and ischemia-reperfusion injury in cardiomyocytes, Eur. J. Pharmacol., 2007, 566, 58-66.

53 M. Yousefian, N. Shakour, H. Hosseinzadeh, A. W. Hayes, F. Hadizadeh and G. Karimi, The natural phenolic compounds as modulators of NADPH oxidases in hypertension, Phytomedicine, 2018, 55, 200-213.

54 E. Cadenas and A. Boveris, Enhancement of hydrogen peroxide formation by protophores and ionophores in antimycin-supplemented mitochondria, Biochem. J., 1980, 188, 31-37.

55 A. Boveris, S. Lores Arnaiz, J. Bustamante, S. Alvarez, L. Valdez, A. D. Boveris and A. Navarro, Pharmacological regulation of mitochondrial nitric oxide synthase, Methods Enzymol., 2002, 359, 328-339.

56 A. Navarro, R. Torrejon, M. J. Bández, J. M. Lopez-Cepero and A. Boveris, Mitochondrial function and mitochondriainduced apoptosis in an overstimulated rat ovarian cycle, Am. J. Physiol. Endocrinol. Metab., 2005, 289, 1101-1109.

57 E. Estornell, R. Fato, F. Pallotti and G. Lenaz, Assay conditions for the mitochondrial NADH:Coenzyme Q oxidoreductase, FEBS Lett., 1993, 332, 127-131.

58 M. E. Murphy and E. Noack, Nitric oxide assay using the hemoglobin method, Methods Enzymol., 1994, 233, 240250.

59 R. K. Emaus, R. Grunwald and J. J. Lemasters, Rhodamine 123 as a probe of transmembrane potential in isolated ratliver mitochondria: spectral and metabolic properties, Biochim. Biophys. Acta, 1986, 850, 436-448.

60 A. Baracca, G. Sgarbi, G. Solaini and G. Lenaz, Rhodamine 123 as a probe of mitochondrial membrane potential: evaluation of proton flux through $\mathrm{F}(0)$ during ATP synthesis, Biochim. Biophys. Acta, 2003, 1606, 137-146.

61 R. C. Scaduto Jr. and L. W. Grotyohann, Measurement of mitochondrial membrane potential using fluorescent rhodamine derivatives, Biophys. J., 1999, 76, 469-477.

62 A. Boveris, Determination of the production of superoxide radicals and hydrogen peroxide in mitochondria, Methods Enzymol., 1984, 105, 429-435.

63 O. H. Lowry, N. J. Rosebrough, A. L. Farr and R. J. Randall, Protein measurement with the Folin phenol reagent, J. Biol. Chem., 1951, 193, 265-275.

64 R. Lagoa, I. Graziani, C. Lopez-Sanchez, V. Garcia-Martinez and C. Gutierrez-Merino, Complex I and cytochrome $c$ are molecular targets of flavonoids that inhibit hydrogen peroxide production by mitochondria, Biochim. Biophys. Acta, 2011, 1807, 1562-1572.

65 C. G. Fraga, M. Galleano, S. V. Verstraeten and P. I. Oteiza, Basic biochemical mechanisms behind the health benefits of polyphenols, Mol. Aspects Med., 2010, 31, 435-445.

66 F. Dajas, A. C. Andrés, A. Florencia, E. Carolina and R. M. Felicia, Neuroprotective actions of flavones and flavonols: mechanisms and relationship to flavonoid structural features, Cent. Nerv. Syst. Agents Med. Chem., 2013, 13, 3055.

67 G. Filomeni, I. Graziani, D. De Zio, L. Dini, D. Centonze, G. Rotillio and M. R. Ciriolo, Neuroprotection of kaempferol by autophagy in models of rotenone-mediated acute toxicity: possible implications for Parkinson's disease, Neurobiol. Aging, 2012, 33, 767-785.

68 A. A. Gerencser, C. Chinopoulos, M. J. Birket, M. Jastroch, C. Vitelli, D. G. Nicholls and M. D. Brand, Quantitative measurement of mitochondrial membrane potential in cultured cells: calcium-induced de- and hyperpolarization of neuronal mitochondria, J. Physiol., 2012, 590, 2845-2871.

69 S. S. Korshunov, V. P. Skulachev and A. A. Starkov, High protonic potential actuates a mechanism of production of reactive oxygen species in mitochondria, FEBS Lett., 1997, 416, 15-18.

70 A. A. Starkov and G. Fiskum, Regulation of brain mitochondrial $\mathrm{H}_{2} \mathrm{O}_{2}$ production by membrane potential and $\mathrm{NAD}(\mathrm{P})$ H redox state, J. Neurochem., 2003, 86, 1101-1117.

71 R. J. Hansford, B. A. Hogue and V. Mildaziene, Dependence of $\mathrm{H}_{2} \mathrm{O}_{2}$ formation by rat heart mitochondria on substrate availability and donor age, J. Bioenerg. Biomembr., 1997, 29, 89-95.

72 V. P. Skulachev, Uncoupling: new approaches to an old problem of bioenergetics, Biochim. Biophys. Acta, 1998, 1363, 100-124.

73 A. Stroh, O. Anderka, K. Pfeiffer, T. Yagi, M. Finel, B. Ludwig and H. Schägger, Assembly of respiratory complexes I, III, and IV into $\mathrm{NADH}$ oxidase supercomplex stabilizes complex I in Paracoccus denitrificans, J. Biol. Chem., 2004, 279, 5000-5007.

74 E. Schäfer, H. Seelert, N. H. Reifschneider, F. Krause, N. A. Dencher and J. Vonck, Architecture of active mammalian respiratory chain supercomplexes, J. Biol. Chem., 2006, 281, 15370-15375.

75 E. N. Dedkova, X. Ji, S. L. Lipsius and L. A. Blatter, Mitochondrial calcium uptake stimulates nitric oxide production in mitochondria of bovine vascular endothelial cells, Am. J. Physiol. Cell Physiol., 2004, 286, C406-C415.

76 D. J. Dorta, A. A. Pigoso, F. E. Mingatto, T. Rodrigues, I. M. Prado, A. F. Helena, S. A. Uyemura, A. C. Santos and C. Curti, The interaction of flavonoids with mitochondria: effects on energetic processes, Chem.-Biol. Interact., 2005, 152, 67-78.

77 J. F. Stevens, J. S. Revel and C. S. Maier, Mitochondriacentric review of polyphenol bioactivity in cancer models, Antioxid. Redox Signaling, 2018, 29, 1589-1611. 